\title{
Evaluating the Impact of the Spatial Distribution of Land Management Practices on Water Erosion: Case Study of a Mediterranean Catchment
}

\author{
Silvio Jose Gumiere, Ph.D. ${ }^{1}$; Jean-Stephane Bailly, Ph.D. ${ }^{2}$; Bruno Cheviron, Ph.D. ${ }^{3}$; Damien Raclot, Ph.D. ${ }^{4}$; \\ Yves Le Bissonnais, Ph.D. ${ }^{5}$; and Alain N. Rousseau, Ph.D. ${ }^{6}$
}

\section{Introduction}

The spatial distribution of land management practices (LMPs) in an agricultural catchment determines the capacity of any given part of the catchment to reduce or increase the global sedimentological connectivity (Cammeraat and Imeson 1999; Fitzjohn et al. 1998). Fryirs et al. (2007), in a work on large-scale systems, proposed that

${ }^{1}$ Professor, Departement des sols et de genie agroalimentaire, Université Laval, QC, Canada.

${ }^{2}$ Researcher, AgroParisTech Laboratoire d'étude des interactions solagrosystème-hydrosystème (LISAH), Montpellier, France (corresponding author). E-mail: silvio-jose.gumiere@fsaa.ulaval.ca

${ }^{3}$ Researcher, National Research Institute of Science and Technology for Environment and Agriculture (IRSTEA), UMR G-eau, Montpellier, France.

${ }^{4}$ Researcher, Institut de recherche pour le développement (IRD)UMR LISAH-Laboratoire d'étude des interactions sol-agrosystèmehydrosystème, Montpellier, France.

${ }^{5}$ Researcher, The French National Institute for Agricultural Research (INRA)-UMR LISAH-Laboratoire d'étude des interactions solagrosystème-hydrosystème, Montpellier, France.

${ }^{6}$ Professor, Institut National de la Recherche Scientifique, Centre Eau, Terre et Environnement (INRS-ETE), Université du Quebec, 490 Rue de la Couronne, Quebec, QC, Canada G1K 9A9. the effects of vegetated filters in catchments depend on their scale and their location relative to the sediment conveyance channels.

Distributed erosion models, therefore, can be used to provide relevant information to managers, planners, and policymakers for the prediction or explanation of the impact of LMPs on soil erosion and sediment transport (Boardman 2006). A sine qua non condition for the models is that they must be able to detect variations in the spatial distribution of LMPs within catchments (Gumiere et al. 2011b). Using the STREAM model (Cerdan et al. 2002), Lecomte (1999) showed that a change in the spatial distributions of grass strips over a catchment had a greater impact on total runoff and sediment trapping than a variation in the size of grass strips in the same location.

From an economic point of view, the implementation and maintenance of LMPs and cropland loss represent the major costs associated with LMPs. Moreover, LMPs are the subject of various government policies and guidelines, such as location and dimensioning (width, proportion of cropland dedicated to conservation areas). In comparing different provincial, territorial, and state guidelines for riparian buffers in the United States and Canada, Lee et al. (2004) found that recommended widths vary between 15.1 and $29.0 \mathrm{~m}$ on average, and in some cases the widths can reach up to $100 \mathrm{~m}$ for different river types. The guidelines are often based on water body type and size, shore lines, and the presence of fish. Lee et al. (2004) argued that simple approaches, such as one size fits all for riparian vegetated filter strip (RVFS) width recommendations, were common in southeastern, northeastern, and midwestern North America. However, more complicated management 
approaches are widespread elsewhere, such as in the North American Pacific region, including Alaska, and the boreal region, where water body type, water body size class, shoreline slope, and fish presence are used to specify riparian buffer width.

Numerical experiments help quantify how hydrological fluxes depend on the spatial characteristics of catchments, which is especially important when the required spatial configurations to be tested are too numerous to use field experiments (Colin et al. 2012). Numerical experiments usually require linking a physically based and spatially distributed hydrological model to a catchment characteristics generator (Van Nieuwenhuyse et al. 2011). In realistic cases, such a conceptual representation of catchment behavior involves several parameters and probable interactions among them, which forces the use of dedicated sensitivity analysis methods.

Sensitivity analysis methods are generally categorized (Saltelli et al. 1999, 2004) into global or local methods, the latter often consisting of differential analysis or nominal range methods (Frey and Patil 2002; Helton 1993). Differential analysis approximates partial derivatives of model outputs with respect to the imposed perturbations in the model inputs and then takes the numerical values of these derivatives as measures of sensitivity. Nominal range methods calculate the relative deviation of outputs from reference (nominal) values and do the same for input values. These methods then express sensitivity as the ratio of relative deviations in output values to that of input values. A known drawback of simple local sensitivity analysis methods is their inability to identify interactions among input parameters, risking erroneous sensitivity estimations, especially for models with large parameterizations or highly nonlinear characteristics. In such contexts, global sensitivity methods are often more suitable.

Global sensitivity analysis methods, such as regional sensitivity analysis (RSA) (Young 1978), variance-based methods (Saltelli et al. 2000, 2010), and regression-based approaches (Spear et al. 1994), attempt to fully explore the parameter space within predefined plausible parameter ranges. The Sobol method is appropriate for models in which cross effects among input parameters exist (Saltelli 2002). For spatially distributed parameter values of relatively large systems, however, Sobol sensitivity analyses suffer limitations due to the heavy computational demands resulting from the need to account for multiple combinations of parameters (Lilburne and Tarantola 2009; Hall et al. 2005). Thus, a strategy to model the aleatory uncertainty in the spatial distribution of input parameters should be designed and should consider reduced parameterizations. As noted by Marrel et al. (2008), the spatial distributions of LMPs would be best tested using few parameters and limiting the dimensionality of the problem.

In the present study, the impact of the spatial distributions of LMPs is analyzed using a numerical analysis that combines the spatially distributed MHYDAS-Erosion model (Gumiere et al. 2011a), a random generator of LMP locations, and the Sobol sensitivity indicator. The upslope-downslope distribution of LMPs is modeled and simulated using a stochastic model and is defined along a specific upstream-downstream location index. The positions of the LMPs are controlled by a set of three parameters. The authors calculate the usual Sobol sensitivity indices to highlight the influences of these three parameters in a deterministic framework using numerous triplets of parameter values, an approach that corresponds to Latin hypercube samplings involving one value in the bounded uncertainty interval of each parameter. The objective here is not to perform a complete sensitivity analysis of the model; the authors are only interested in the impact of the spatial variability of LMPs on soil erosion.

The second section presents the study site, MHYDAS-Erosion, the stochastic model, and the sensitivity analysis procedure. In a subsection of the second section, the authors present a detailed description of the stochastic LMP location generator model, the coupling between the stochastic model, and MHYDAS-Erosion within SENSAN and the Sobol sensitivity analysis method. In the third section, the authors present the model response to the spatial distribution of LMPs on the Roujan catchment by analyzing soil losses at three measurement points. First- and total-order Sobol sensitivity indices are also presented. The conclusion is presented in the fourth section.

\section{Materials and Methods}

\section{Study Site}

The study site is an experimental catchment belonging to the Observatoire Méditerranéen de l'Environnement Rural et de l'Eau (OMERE) long-term hydrometeorological observatory (http:// www.umr-lisah.fr/omere) called Roujan $(43.300 \mathrm{~N}, 3.190 \mathrm{E}$, area $1 / 4$ $0.91 \mathrm{~km}^{2}$ ). The observatory has been densely instrumented with hydrometeorological equipment (Fig. 1). The authors chose to use only three measurement points, corresponding to two subcatchment outlets, one in the headwater and the other near the outlet. These two subcatchments (Points 2 and 3 in Fig. 1) were selected because they are not in a cascade system, so they do not interact. Approximately $20 \%$ of the agricultural fields have a vegetated filter downstream. For simplicity, the authors consider that these vegetated filters behave like grass strips from a phenomenological point of view.

The annual rainfall varies between 500 and 1,400 mm, showing a bimodal temporal distribution with two major rainy periods - one in spring and the other in autumn. Rainfall is usually of high intensity and short duration. The mean annual temperature is approximately $14^{\circ} \mathrm{C}$, and the mean annual Penman evapotranspiration is $1,090 \mathrm{~mm}$. The soils of the catchment developed from marine, lacustrine, or fluvial sediments (Moussa et al. 2002). The catchment is mainly covered by vineyards and is divided into 237 agricultural fields. The areas of the agricultural fields vary between 0.03 and 2.2 ha. The drainage network is very dense, is formed by humanmade ditches, and generally follows the boundaries of the agricultural fields. The total length of the ditch network is $11,069 \mathrm{~m}$ (drainage density of $1.21 \times 10^{-2}=\mathrm{m}$ ).

\section{Erosion Model}

The MHYDAS-Erosion (Gumiere et al. 2011a) model is coupled with the MHYDAS hydrological model (Moussa et al. 2002). The latter partitions rain between infiltration and runoff according to the method introduced by Morel-Seytoux (1978) and analytically solves the one-dimensional diffusive wave equation for concentrated flows in the linear elements (drainage network) of the catchment (Moussa and Bocquillon 1996; Moussa 1996). The calculated excess-infiltration runoff depends on saturated, vertical, and hydraulic conductivity and initial water content, which govern water infiltration. Flow depth and velocity are then obtained from discharge by means of the Manning equation from the known slope and width of each reach segment draining a plot. The erosion module requires, at minimum, a finer decomposition of flow regions into subsections of adaptable sizes representing rill and interrill areas associated with different phenomenologies [further details on MHYDAS-Erosion can be found in Gumiere et al. (2011a)]. Computed on time steps fine enough to correctly track the fastest flow expected, the flow velocities were also redefined to ensure the stability of the model according to the Courant-Friedrichs-Lewy condition (Courant et al. 1928). 


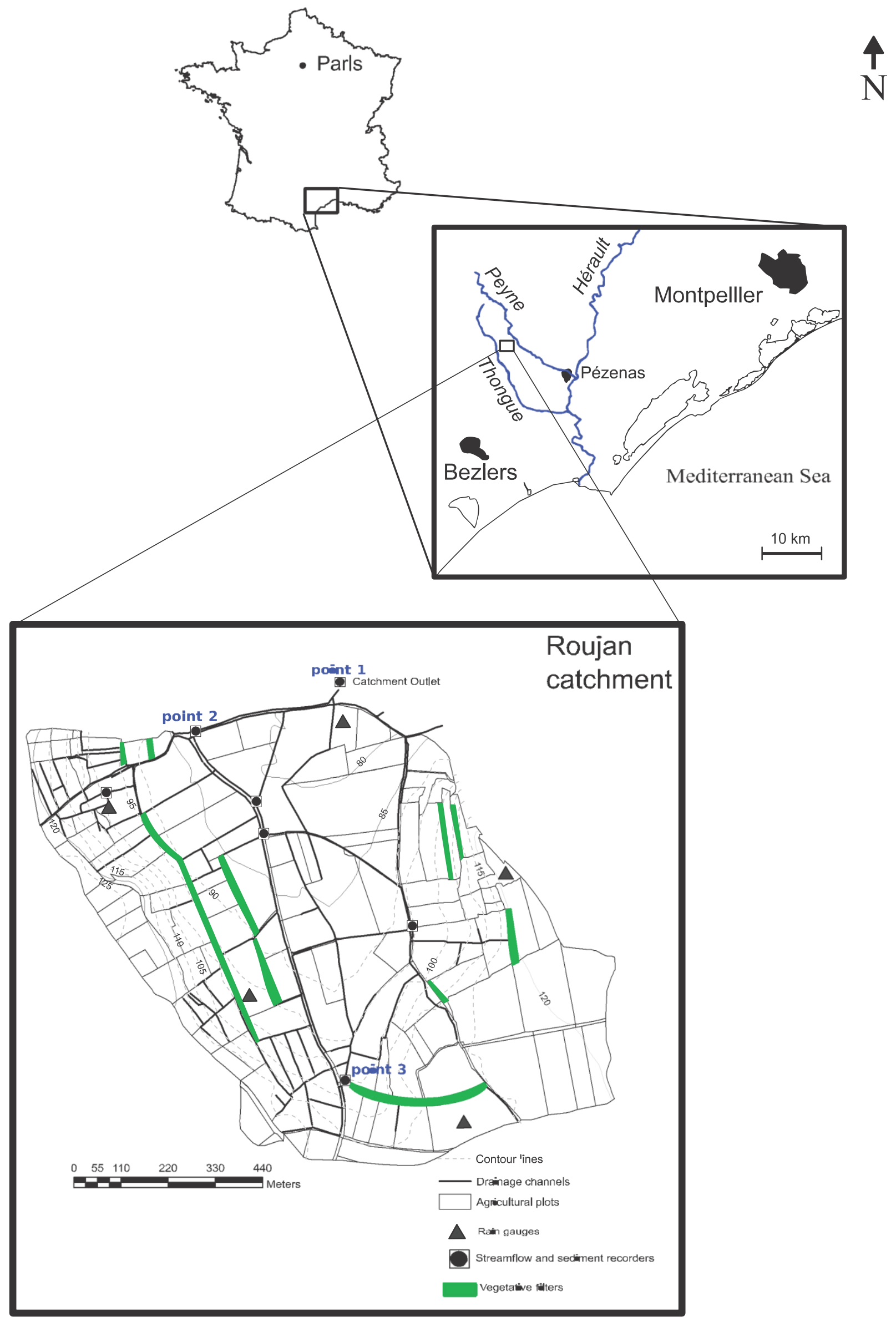

Fig. 1. (Color) Measurement network of Roujan catchment, France, and its LMP locations (data from OMERE 2009) 
Table 1. Input Parameters of MHYDAS-Erosion

\begin{tabular}{|c|c|c|}
\hline Parameter & Description & Unit \\
\hline \multicolumn{3}{|l|}{ SU } \\
\hline $\mathrm{ks}$ & Saturated hydraulic conductivity & $\mathrm{m}=\mathrm{s}$ \\
\hline hc & Air entry potential & $\mathrm{m}$ \\
\hline$\theta_{\mathrm{r}}$ & Soil residual moisture & $\mathrm{m}^{3}=\mathrm{m}^{3}$ \\
\hline$\theta_{\mathrm{s}}$ & Soil saturation moisture & $\mathrm{m}^{3}=\mathrm{m}^{3}$ \\
\hline $\mathrm{n}_{\mathrm{SU}}$ & Manning's roughness coefficient & $\mathrm{sm}^{-1=3}$ \\
\hline $\mathrm{A}_{\mathrm{s}}$ & Aggregate stability index & - \\
\hline $\mathrm{N}_{\text {rill }}$ & Number of rills & - \\
\hline $\mathrm{W}$ & Rill width & $\mathrm{m}$ \\
\hline $\mathrm{d}_{50}$ & Median sediment diameter & $\mathrm{m}$ \\
\hline$\tau_{\mathrm{c}}$ & Critical soil shear stress & $\mathrm{Pa}$ \\
\hline $\mathrm{LMP}_{\text {code }}$ & LMP type indicator & - \\
\hline $\mathrm{K}_{\mathrm{r}}$ & Rill erodibility & $\mathrm{s}=\mathrm{m}$ \\
\hline cetimax & furboni inmtenrithespsirancoefficient & - \\
\hline 1 & Vegetated filter width & $\mathrm{m}$ \\
\hline B0 & Unit flow width not blocked by grass & - \\
\hline \multicolumn{3}{|c|}{ 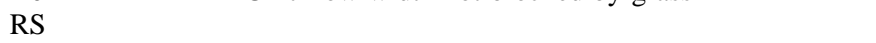 } \\
\hline $\mathrm{ks}$ & Saturated hydraulic conductivity & $\mathrm{m}=\mathrm{s}$ \\
\hline $\mathrm{n}_{\mathrm{RS}}$ & Manning's roughness coefficient & $\mathrm{sm}^{-1=3}$ \\
\hline $\mathrm{K}_{\mathrm{r}}$ & Rill erodibility & $\mathrm{s}=\mathrm{m}$ \\
\hline$\tau_{\mathrm{c}}$ & Critical soil shear stress & $\mathrm{Pa}$ \\
\hline
\end{tabular}

MHYDAS-Erosion has been designed to simulate runoff and erosion processes from isolated rainfall events in agricultural catchments. The model is based on the spatial segmentation of a catchment, where agricultural fields are represented by homogeneous polygons called surface units (SUs) and the network of drainage channels is depicted by a series of interconnected reach segments (RSs). A semiautomatic geographic information system (GIS) vector-based procedure (Lagacherie et al. 2010) allows for easy segmentation and, in turn, facilitates the parameterization of the hydrological objects. The processes incorporated into the model are rainfall, infiltration, overland flow, channel flow, soil detachment by rainfall, soil detachment and deposition by overland flow, and soil detachment and deposition by channel flow. The model has a module with which to describe the influence of LMPs on sedimentological connectivity. In this first version of MHYDASErosion, LMPs are limited to vegetative filters located between SUs or between one SU and a draining RS. Table 1 shows the input parameters and descriptions used in MHYDAS-Erosion.

The sedimentological connectivity module of MHYDASErosion controls the sediment transfer between two hydrological objects $(\mathrm{SU} \rightarrow \mathrm{SU}, \mathrm{SU} \rightarrow \mathrm{RS}$, and $\mathrm{RS} \rightarrow \mathrm{RS})$. This version of MHYDAS-Erosion only takes into account LMPs falling into the broad category of vegetated filters: grass strips, vegetated waterways, and riparian zones. The parameter $\mathrm{LMP}_{\text {code }}$ indicates which type of LMP is applied to a given hydrological object: if $\mathrm{LMP}_{\text {code }} 1 / 40$, then no LMP is applied. If $\mathrm{LMP}_{\text {code }} 1 / 41$, then an LMP is applied downstream from the corresponding SU.

In MHYDAS-Erosion, sediment filtration provided by a grass strip is based on flume experiments conducted by Deletic (2001) and Deletic and Fletcher (2006). The sediment-trapping efficiency $\left(\mathrm{T}_{\mathrm{r}}\right)$ is defined as a function of the nondimensional particle fall number $\mathrm{N}_{\mathrm{f}}$

where

$$
\mathrm{T}_{\mathrm{r}} 1 / 4 \frac{\mathrm{N}_{\mathrm{f}}^{0.69}}{\mathrm{f}^{0.69} 4.95}
$$

$$
\mathrm{N}_{\mathrm{f}} 1 / 4 \frac{1 \cdot \mathrm{V}}{\mathrm{h}_{\mathrm{w}} \cdot \mathrm{V}}
$$

where 1 = width of the grass $\operatorname{strip}(\mathrm{m}) ; \mathrm{V}_{\mathrm{s}}=$ Stokes velocity for the settling of sediment particles $(\mathrm{m}=\mathrm{s}) ; \mathrm{h}_{\mathrm{w}}=$ water height $(\mathrm{m})$; and $\mathrm{V}=$ mean flow velocity between grass blades $(\mathrm{m}=\mathrm{s})$. The mean flow and settling velocities in the model are calculated as follows:

$$
\mathrm{V} 1 / 4 \frac{\mathrm{q}}{\mathrm{B}_{0} \cdot \mathrm{h}_{\mathrm{w}}}
$$

and

$$
\mathrm{V}_{\mathrm{s}} 1 / 4 \frac{\mathrm{g}}{18 \mu} \partial \rho_{\mathrm{s}}-\rho \mathrm{Pd}_{\mathrm{s}}^{2}
$$

where $\mathrm{q}=$ flow rate per unit of hillslope width $\left(\mathrm{m}_{2}=\mathrm{s}\right) ; \mathrm{B}_{0}=$ unit flow width not blocked by grass $(-) ; \mu=$ dynamic viscosity of water $(\mathrm{kg}=\mathrm{s}=\mathrm{m}) ; \rho=$ water density $\left(\mathrm{kg}=\mathrm{m}^{3}\right) ; \rho_{\mathrm{s}}=$ sediment particle

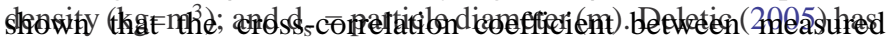
and calculated trapping efficiencies reached $R^{2} 1 / 40.85$, which is acceptable.

In MHYDAS-Erosion, $T_{r}$ is calculated for each time step, making sediment-trapping efficiency time dependent. The parameters $\mathrm{B}_{0}$ and 1 are estimated from field observations and may be spatially distributed in the catchment. For the present tests, the authors adopted constant values of $\mathrm{B}_{0} \partial 0.5 \mathrm{P}$ and $1(2 \mathrm{~m})$ for all grass strips in the catchment.

\section{Numerical Experiment Procedure and Stages}

The procedure used to assess the impact of the spatial distributions of LMPs follows a three-step sequence. The first step consists in developing a stochastic model defining the distributions of LMPs along upslope-downslope branches of the surface flow chart. The second step matches the input requirements of MHYDAS-Erosion with those of the conceptual stylized representation. The third step calculates the global Sobol indices that trace the influence of the upstream-downstream distribution of LMPs on MHYDAS-Erosion outputs.

Stochastic Generation of LMP Locations

The transfer of water and sediment in MHYDAS-Erosion is constrained by a process-oriented topology in which the links between hydrological objects (SU and RS) are made in a descending upslope-downslope procedure that allows no reverse upward advection resulting from backwater phenomena. Moreover, the fluxes of water and sediment from a surface unit can only be gathered, not divided: confluence is allowed, difluence is not. Therefore, neither loops nor bifurcations exist in the flow patterns. Conversely, a surface unit may receive water and sediment from one or more hydrological objects. Consequently, the topology allowed in MHYDAS-Erosion for the Roujan catchment corresponds to the downstream-oriented tree shown in Fig. 2(a). In Fig. 2(b), the authors chose to project the tree on an ordinate corresponding to the distance of the hydrological objects to the main outlet of the flow network. Thus, the locations of LMPs generated by the stochastic process can be unambiguously identified along this ordinate (called the h-ordinate, representing the distance of sources to the outlet of the catchment), which thus bears every tested configuration of LMPs in the catchment according to flow paths. The abscissa values simply indicate a junction order.

The potential sites for LMPs are flagged by $1 / 2 p \&$ symbols in Fig. 2(b). Two types of connections are possible, from SU to SU and from SU to RS, wherever water and sediment discharge may occur. For the purpose of the present sensitivity analysis, the authors decided to apply LMPs only to SUs, thereby allowing both types of connection. Here, LMPs are exemplified as grass 


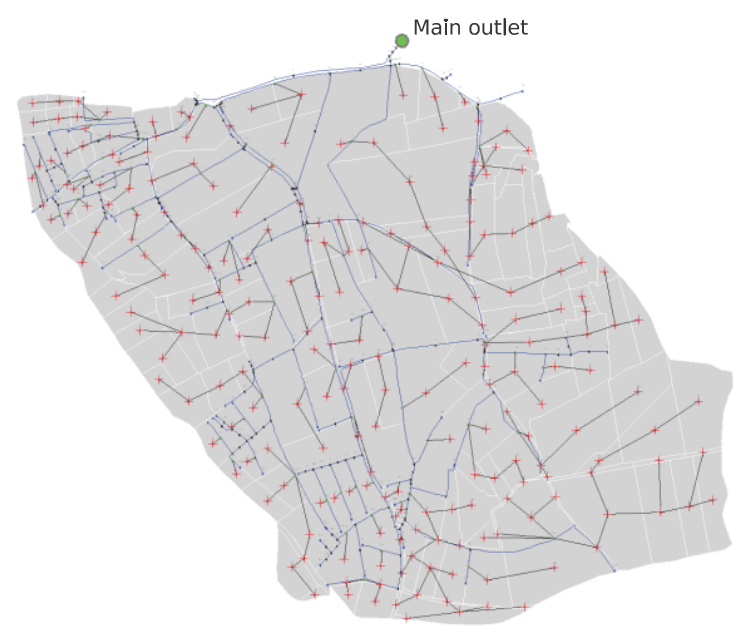

(a)

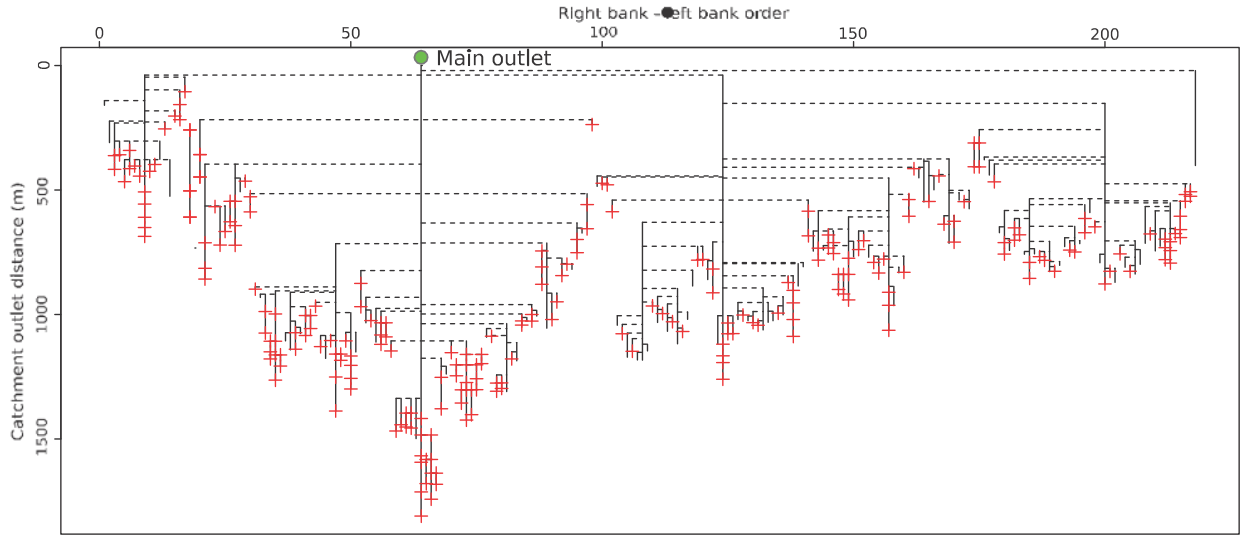

outlet catchment

+ land management posslble place

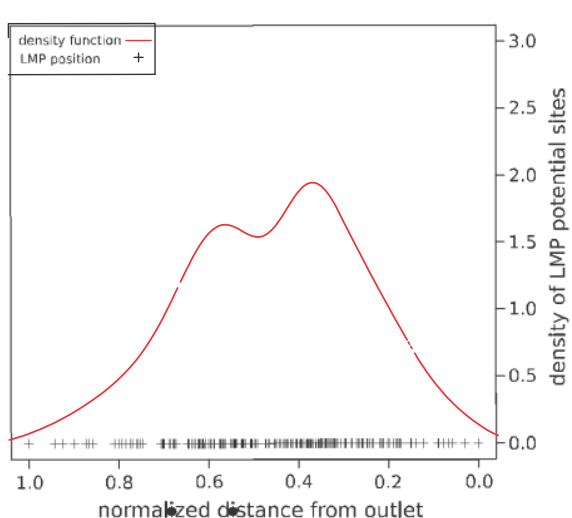

(c)

(b)

Fig. 2. (Color) Schematic view of locations of land management practices (LMPs) over Roujan catchment: (a) catchment topology representation; (b) catchment represented as directed tree with potential LMP sites; (c) probability density function (PDF) of potential LMP sites (data from OMERE 2009)

strips applied downslope of a SU. Fig. 2(c) shows all potential sites for LMPs projected along the h-axis and the resulting smoothed kernel of the associated probability density function (line).

First, the $\mathrm{h}$ index is transformed for convenience into a normalized $\mathrm{x}$ index ranging from 0 (outlet) to 1 (farthest source from outlet)

$$
\mathrm{x} 1 / 4 \frac{\mathrm{h}}{\max u \mathrm{~h} r}
$$

The main principle of the stochastic generation of LMP locations is to randomly select a number of LMPs from potential sites $1 / 2 b \&$ using a probability assigned to each potential site. This probability is determined by $r$, the LMP density parameter controlling the total number of LMPs generated, and by $\mathrm{p}$ and bw, which control their locations along the upslope-downslope x-axis. From the given values of these three scalar parameters, an upslopedownslope probability function $\mathrm{g} ð \mathrm{xP}$ is built. According to $\mathrm{g} ð \mathrm{xP}$, potential sites $1 / 2$ p\& are randomly selected for LMP locations. Stochasticity in the process is ensured through random sampling with respect to $\mathrm{g} ð \mathrm{xP}$.
To model contrasted upslope-downslope configurations of LMPs, the authors propose a linear upslope-downslope probability density function, gðxp, which is defined for any location $\mathrm{x}$ as follows:

$$
\operatorname{gðxP~} 1 / 4^{!} \frac{1 \text { p p }}{2}-ð p \cdot x P
$$

where $\mathrm{p}=$ upstream-downstream gradient of LMPs, ranging from -1 to 1 . When $\mathrm{p} 1 / 40$, all potential sites have the same probability of being selected, regardless of the $x$ value. When $\mathrm{p}^{1 / 4}-1$, it is more probable that the potential upstream LMP sites will be selected than the potential downstream sites. Conversely, when p $1 / 41$, the potential downstream sites of LMPs will more likely be selected than the potential upstream sites.

For a given catchment, intrinsic potential sites are not distributed with the same density along the upstream-downstream axis, which can be described by the preceding equations. To increase the flexibility of the procedure and especially to amplify the contrast between upstream and downstream locations, the authors added a second-order parameter to the description. This parameter, denoted by bw, corresponds to the bandwidth of the kernel used to estimate 
the probability density function of potential LMP sites (PDFL) along the upslope-downslope axis [Fig. 2(c)]. The inverse of the probability density function is used as a probability amplifier, i.e., gðxP is convoluted with the inverse of the PDFL and normalized to obtain a total probability of one. Consequently, when bw is large, PDFL is constant and $\mathrm{g} ð \mathrm{xP}$ [Eq. (6)] is not altered. Conversely, when bw is small, PDFL is a nonconstant function [Fig. 2(c)] and gðxP is accordingly corrected and locally amplified.

During simulations, it is necessary to define the number of LMPs placed in the catchment. For this purpose, the authors introduced a density parameter $r$ ranging from 0 to 1 , defined as the ratio between the number of simulated LMPs and the total number of potential sites in the catchment. Practically, $r$ controls the repetition of samplings in the gðxP function (amplified according to bw) until the desired number of simulated LMPs is obtained.

Finally, the LMP locations in the catchment are stochastically simulated through two main parameters, $r$ and $\mathrm{p}$, and a secondorder parameter, bw. Fig. 3 shows the mean upslope-downslope positions of LMPs as calculated within this stochastic model for various values of the control parameters.

In Fig. 3, the mean upslope-downslope positions of LMPs for bw $1 / 40.06$ are more contrasted than for bw $1 / 42$. The effect of $p$
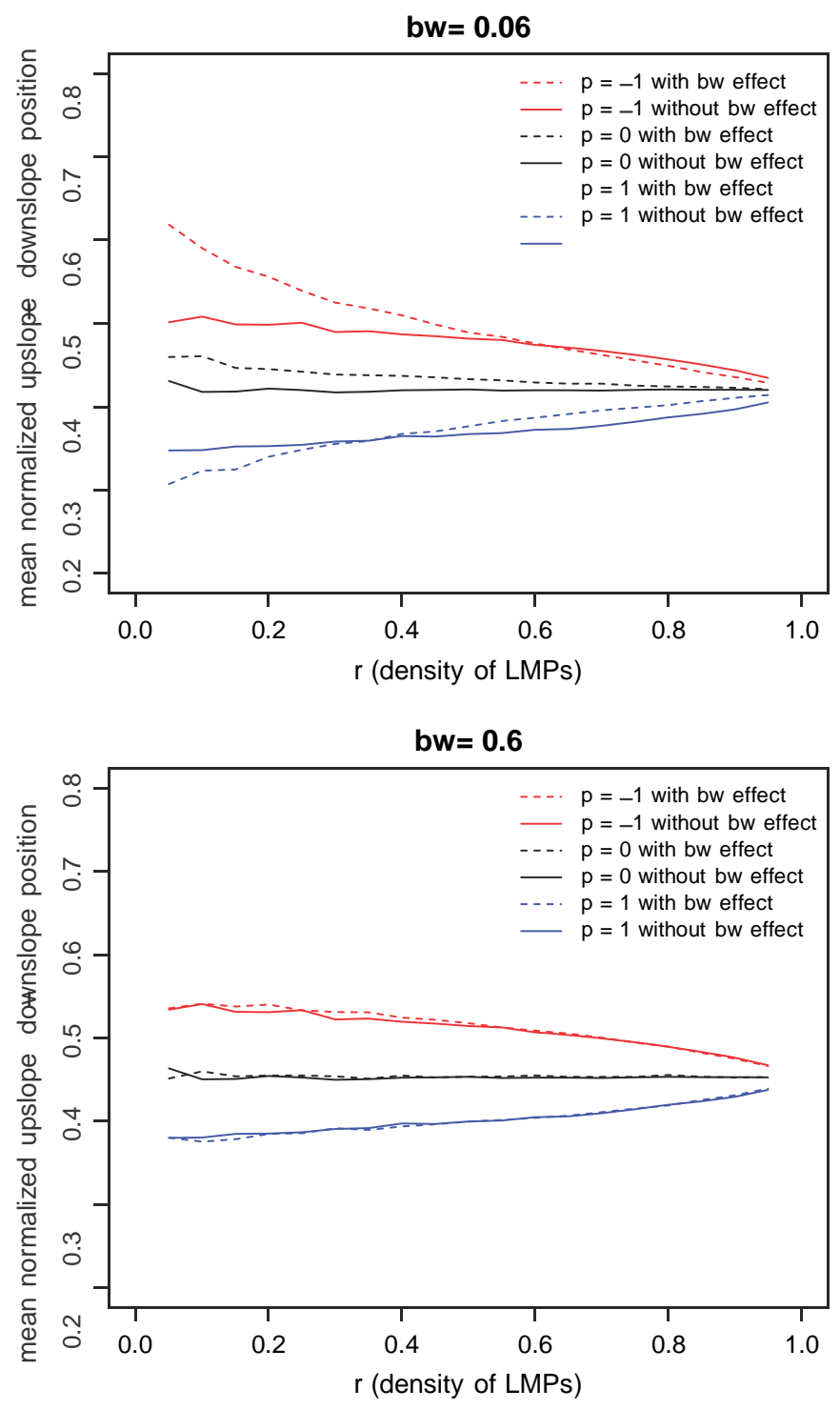

variations is clear: upstream positions are more numerous when p $1 / 41$ and less numerous when p 1/4 -1 . In fact, the bw parameter was introduced to control the influence of the intrinsic hydrological connectivity of the catchment. When bw $1 / 42$, the intrinsic connectivity is maintained. Conversely, when bw $1 / 40.06$, the connectivity is modified and normally distributed throughout the catchment.

Framework to Link the Stochastic Model to MHYDAS-Erosion

Only the three parameters defining the stochastic model were used in the present sensitivity analyses. The sensitivity of MHYDASErosion to the other input parameters has been tested by Cheviron et al. (2010). Sensitivity analyses performed by Cheviron et al. (2010, 2011) identified the most sensitive parameters for MHYDAS-Erosion: $\mathrm{ks}, \mathrm{N}_{\text {rill }}, \mathrm{K}_{\mathrm{r}}$, and $\mathrm{A}_{\mathrm{s}}$. According to Cheviron, MHYDAS-Erosion showed a strong sensitivity to the input flux (control of hydrological factors), such as precipitation and runoff. In fact, some erosion processes represented in MHYDAS-Erosion depend on a threshold value (e.g., strong and short precipitation events associated with strong runoff conditions result in strong rill erosion, whereas weak and long rainfall events may favor interrill erosion). The sensitivity of the model to the soil erosion parameters

bw $=0.2$

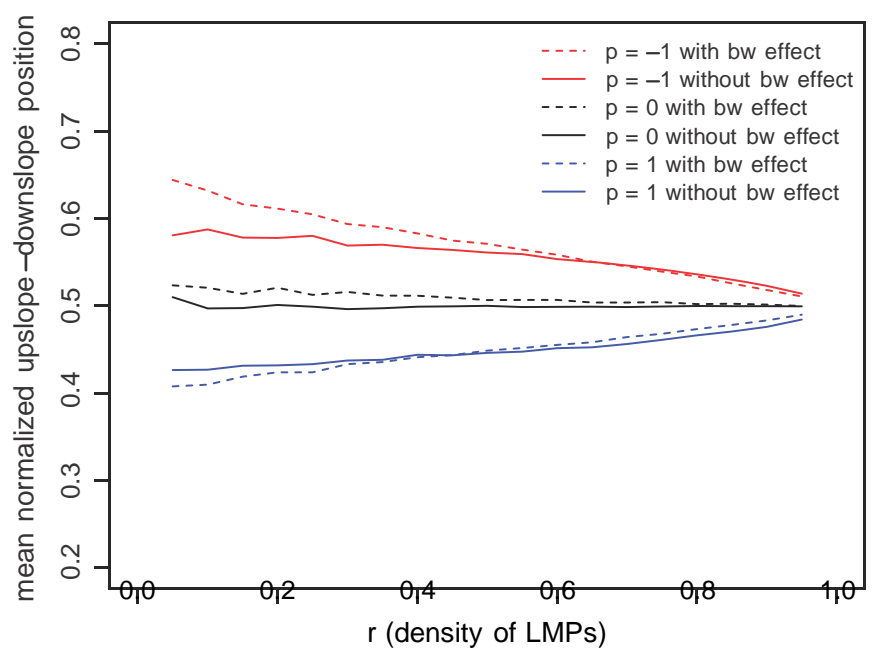

$b w=2$

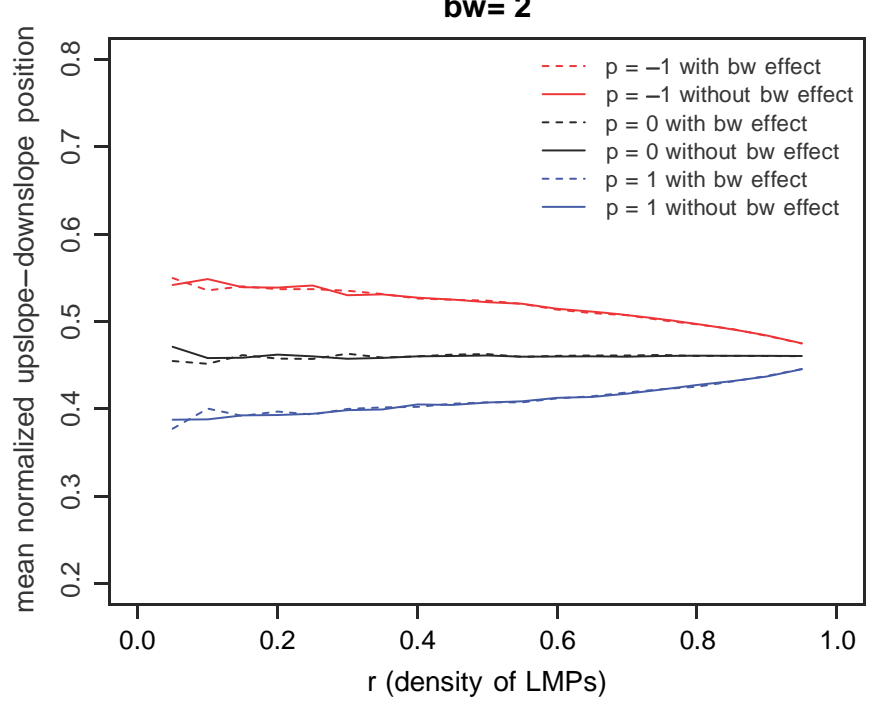

Fig. 3. (Color) Mean normalized distance of LMPs for varied r, p, and bw values 


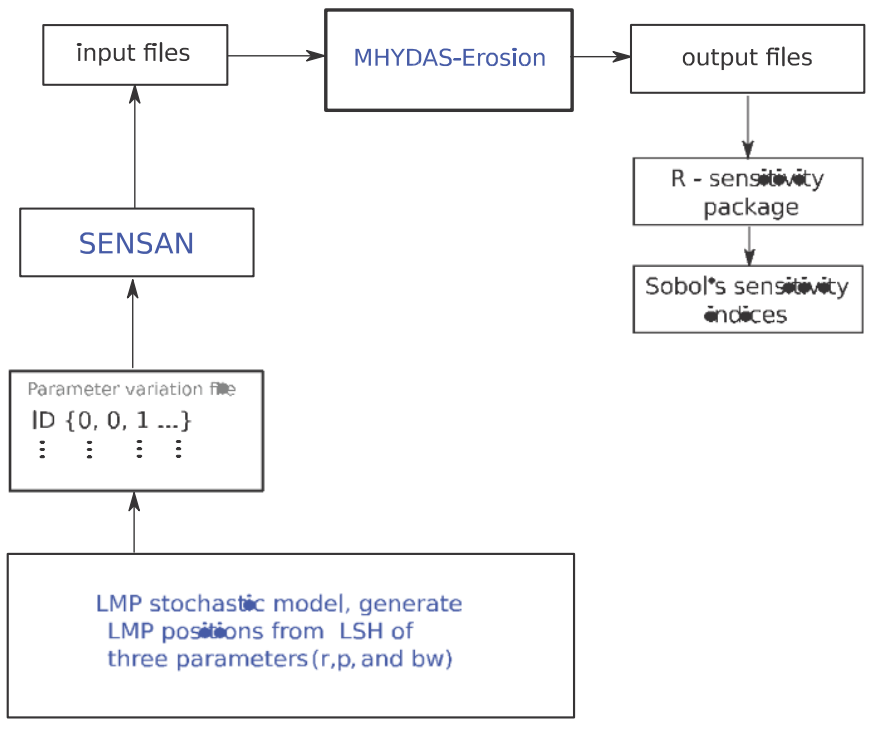

Fig. 4. (Color) Graphic representation of coupling between stochastic LMP position generator model and MHYDAS-Erosion

thus depends on the test configuration, as suggested by Gumiere et al. (2009). To exclude parasite sensitivity effects, all innate parameters required by MHYDAS-Erosion are held constant throughout the catchment for all hydrological objects (SU and RS).

The SENSAN software (Doherty 2004) was used to feed predefined parameter sets to MHYDAS-Erosion and to automate MHYDAS-Erosion runs until all parameter sets were tested. SENSAN acts as a master model to any slave model to which it is linked, provided communication between them is possible through input and output ASCII files. Fig. 4 shows the overall coupling among the stochastic model, SENSAN, and MHYDASErosion.

Based on a quasi-random Sobol sampling of r, p, and bw using the fOptions (Wuertz et al. 2010) package of the R-CRAN software (R Development Core Team 2010), the stochastic model generates the positions of LMPs throughout the catchment. The output of the stochastic model is a binary $\mathrm{LMP}_{\text {code }}$ set that indicates whether the candidate SU has a LMP for each of the 237 SUs in the Roujan catchment. Eighty thousand simulations with MHYDAS-Erosion were run using fixed rainfall characteristics to ensure that the sensitivities stabilized themselves near asymptotic values. A constant rain value of $60 \mathrm{~mm} / \mathrm{h}$ over $4 \mathrm{~h}$ in a single storm event was used in all simulations (a 100-year return period event for the Roujan catchment). First-order and total Sobol sensitivity indices were calculated using the sensitivity package of the RCRAN

software.

Impact of LMP Distribution through the Sobol Indices The Sobol method, described in Sobol (1993) and Saltelli et al. (2000), was used to compute sensitivity indices; this method is a variance-based global sensitivity analysis method using the http://cran.r-project.org/web/packages/sensitivity/ sensitivity package. This method usually yields first-order sensitivity indices (S) and total sensitivity indices (TS) that take into account interactions among factors. The TS of a factor is defined as the sum of all the sensitivity indices involving that factor, alone or in interactions (Saltelli et al. 2008). For example, if a model has three factors $X_{1}, X_{2}$, and $X_{3}$, the TS of the factor $X_{1}$ is given by $S ð X_{1} P p$ S $ð X_{1} X_{2}$ P p SðX $X_{3}$ P p SðX $X_{2} X_{3}$ p, where SðXP denotes the sensitivity index of $X$. $S ð X_{1}$ P refers to the first-order sensitivity index of
$X_{1} . S ð X_{1} X_{2} P$ and $S ð X_{1} X_{3} P$ refer to the interaction effects between $X_{1}$ and $X_{2}$ and between $X_{1}$ and $X_{3}$, respectively. $S ð X_{1} X_{2} X_{3}$ p refers to the interaction effects among $X_{1}, X_{2}$, and $X_{3}$. The Sobol method decomposes the output variance into all possible sources based on a high-dimensional representation of the model.

Indices $\mathrm{S}_{\mathrm{i}}$ and $\mathrm{TS}_{\mathrm{i}}$ for a given $\mathrm{X}_{\mathrm{i}}$ factor correspond to empirical estimations of the variance ratio

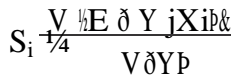

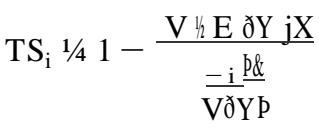

In Eqs. (7) and (8), Y is the model output, VðYp the variance of $\mathrm{Y}$, and EðYP its expectation. $\mathrm{X}_{-\mathrm{i}}$ denotes all other parameters except $\mathrm{X}_{\mathrm{i}}$. VðEðYjXipp is the variance of a conditional expectation of $Y$, having frozen the source of variation $X_{i}$. VðEðYj $X_{-i} p P$ is the variance of the conditional expectation of $Y$, having frozen all sources of variation except $X_{i}$. Consequently, $S_{i}$ ranges from 0 to 1 , and the higher $S_{i}$ is, the more sensitive the model is to $X_{i}$. In the case of additive models, ${ }_{i} S_{i} 1 / 41$. Using the usual Sobol framework on a model with a stochastic component, the authors limit the sensitivity exploration to the deterministic behavior of the model (Iooss et al. 2009; Marrel et al. 2010). As a consequence of this limitation, the $Y$ variability arising from model stochasticity is not taken into account.

However, the Sobol method provides information on isolated or combined influences of the factors as well as insights into the additive or nonlinear behavior of the model. Furthermore, the Sobol method can be smoothly applied to categorical factors without rescaling. The method used to estimate the Sobol indices with a Monte Carlo approach is explained by Saltelli et al. $(2008,2010)$. In the next section, the authors examine variations in the predicted soil loss related to variations in the three control parameters ( $r, p$, and bw) used to generate the LMP locations.

\section{Results and Discussion}

\section{Impact of Upslope-Downslope Positions of LMPs}

First, the authors fixed the range of variations for the control parameters $\mathrm{r}, \mathrm{p}$, and bw to $\hbar_{0}-1 \downarrow, \hbar_{0}-1 \Downarrow$, and $\hbar_{0.06}-2 \downarrow$, respectively, with uniform probability laws and separated these intervals into 20 classes each and performed 800 repetitions within each class ac- cording to the Latin Hypercube sampling design and Sobol method described by Saltelli et al. (2008, p. 165). These collected param- eter sets were used to generate an equal number of spatial distri- butions of LMPs.

Second, a constant rain intensity of $60 \mathrm{~mm}=\mathrm{h}$ over $4 \mathrm{~h}$ was applied for each spatial configuration of LMP. The normalized soil loss results obtained from MHYDAS-Erosion were calculated at the three aforementioned measurement points in the Roujan catchment, allowing for easy comparison between scales. The Normalized Soil Loss (NSL) is calculated for each measurement point as NSL $1 / 4 / 2 E_{i}-\min ð E P \&=k \max ð \mathrm{EP}-\min ð \mathrm{E} \& \&$, where $\mathrm{E}_{\mathrm{i}} ð \mathrm{kgP}$ is the soil loss at a measurement point for the ith simulation and $\mathrm{E}$ is the vector with all simulated erosion values. Fig. 5 shows boxplots of simulated NSL responses to variations in $\mathrm{p}, \mathrm{r}$, and bw values at the three measurement points in the catchment.

Fig. 5 shows the direct relation between the variance of model response and that of individual parameter values, corresponding to 


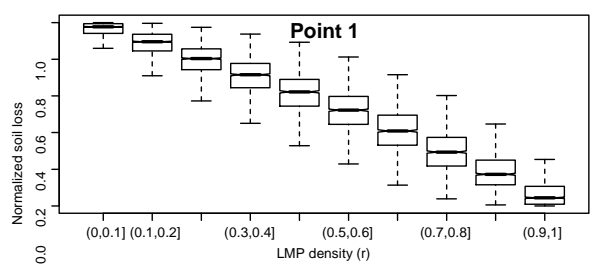

(a)

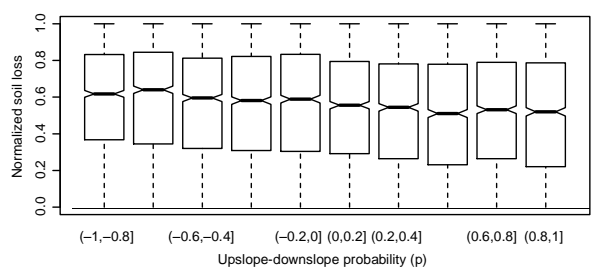

(b)

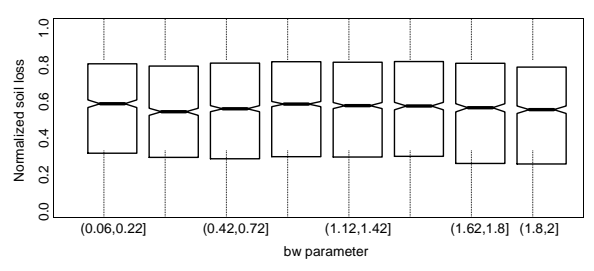

(c)

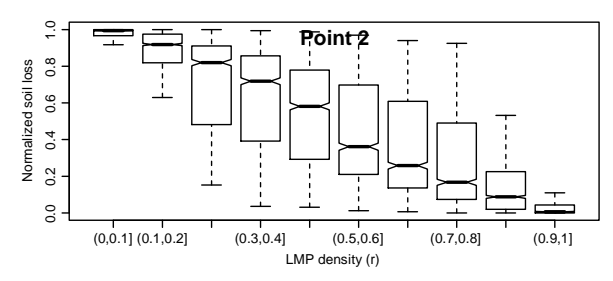

(d)

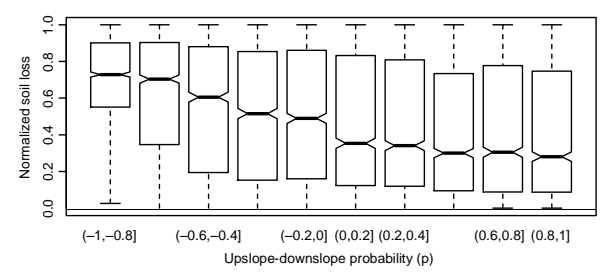

(e)

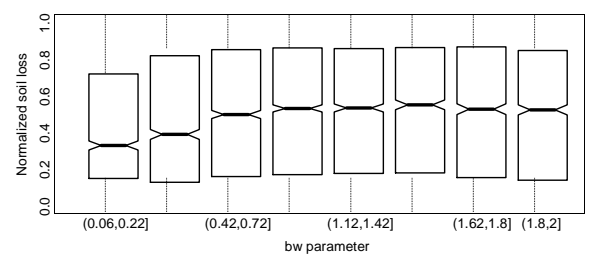

(f)

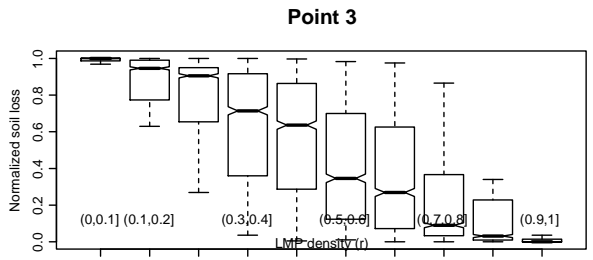

(g)

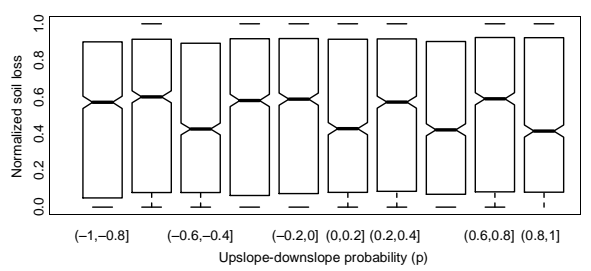

(h)

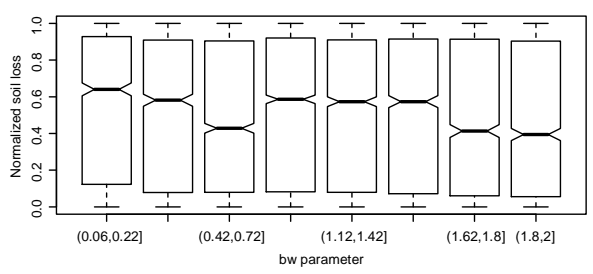

(i)

Fig. 5. Boxplots of simulated NSL responses to variations in $\mathrm{p}, \mathrm{r}$, and bw values; $(\mathrm{a}-\mathrm{c})$ refer to measurement Point 1 ; (d-f) refer to measurement Point 2; $(\mathrm{g}-\mathrm{i})$ refer to measurement Point 3

Eq. (7). From values plotted as the median line, it is obvious that the density of LMP (r) has a scale-dependent effect on NSL. When the density approaches 1, NSL asymptotically decreases to zero, but the variance of NSL at Point 1 (catchment) appears to be smaller than the variances found for measurement Points 2 and 3 at subcatchment scales. In addition, the NSL values calculated at Points 2 and 3 seem to be more sensitive to the upslope-downslope probability (p) and to the bw parameter than the NSL calculated at Point 1. The fact that NSL at the main outlet is less influenced by $\mathrm{p}$ values than at the intermediate measurement points might be explained by the presence of a very dense drainage network $\left(1.21 \times 10^{-2}=\mathrm{m}\right)$, which limits the effect of the p parameter as long as no LMP is applied to the drainage channels.

Fig. 6 shows the best configuration for LMP emplacements regarding the maximum trapping coefficient over the catchment when fixing a specific value of LMP density (r). The boxplot below each map shows the trapping coefficient variation for all possible configurations of emplacements given a fixed value of LMP density. In the first scenario ( $\mathrm{r}^{1 / 4} 0.3$ ), the trapping coefficient varies within a certain range $[0.06,0.46]$. This trapping coefficient range is due to the different possibilities of LMP emplacement over the catchment. Thus, 0.46 is the maximum trapping coefficient for this particular catchment when $30 \%$ of the fields have an LMP. This result also shows that a poor choice of LMP locations may have a large impact on the sediment-trapping efficiency, e.g., at least one configuration has an efficiency of 0.06 . For the last scenario ( $\mathrm{r}^{1 / 4}$ 0.7), indicating that $70 \%$ of the fields have one LMP, the trapping coefficient varies from 0.32 to 0.93 . Even in this condition, with $70 \%$ of the fields having a LMP, a poor recommendation may have a serious impact on the global sediment-trapping efficiency of the catchment.
Global Impact of Distributions of Land Management Practices

Table 2 shows the total and first-order Sobol indices related to the ðr; p; bwP triplet as well as the NSL values obtained at the two subcatchment outlets and at the main catchment outlet.

As expected, the largest sensitivity indices are found for the parameter $r$, accounting for the LMP density. The maximum first-order index is always that of $r$, whatever the subcatchment, and it increases with the drained area. These results indicate that $\mathbf{r}$ is the only parameter influencing soil loss simulation by MHYDAS-Erosion in Roujan at all three points (and for the associated drained areas). In contrast, $p$ has a very small, though nonzero, influence on the prediction. Additionally, bw has no direct influence on the model outputs.

Except for Point 1 (catchment outlet), the sum of the first-order sensitivity indices always remains less than one. This behavior may indicate that the metamodel linking the stochastic generation of LMP to MHYDAS-Erosion has no additive effect for Points 2 and 3, except at the outlet of the catchment, but this result is also due to the neglect of variance arising from the stochastic component of the model in the usual Sobol indices (Iooss et al. 2009; Marrel et al. 2010).

Table 2 indicates that all parameters interact and that the total Sobol indices provide information about these interactions. At Point 1 , a very slight increase of 0.08 in the index of the total effect associated with $r$ reveals only weak interactions, whereas significant interactions are observed for the two subcatchments. The increase from first-order to total sensitivity indices for the $r$, p, and bw parameters has the same order of magnitude at the subcatchment scales (measurement Points 2 and 3), showing a high interaction of the $\mathrm{p}$ and bw parameters with the others at these scales. 


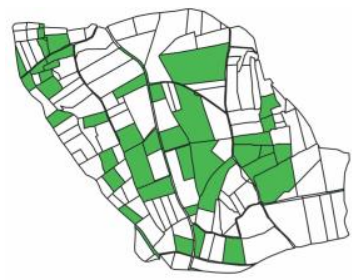

$r=0.3$

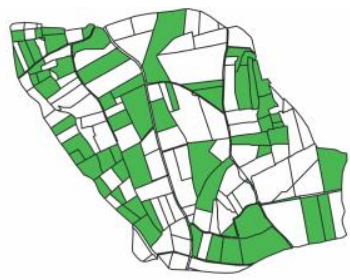

$r=0.4$

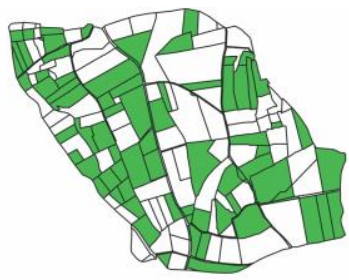

$r=0.5$

Grass strip

$\square$ No grass strip
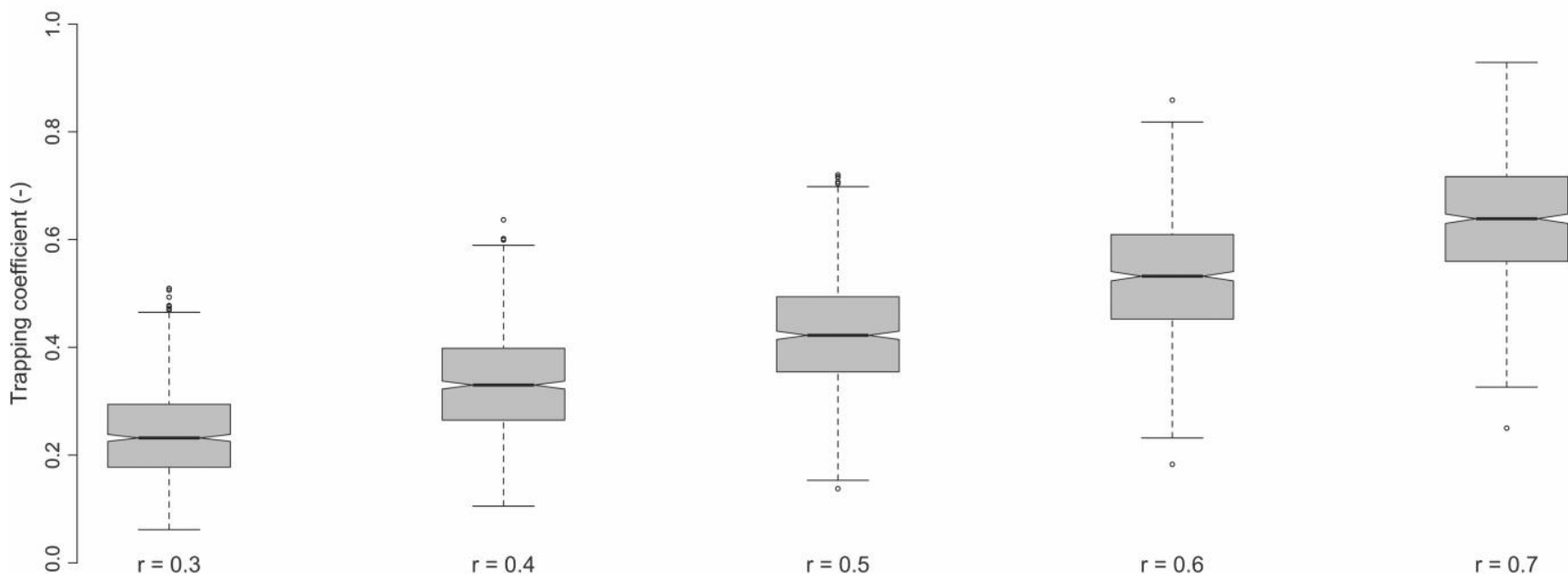

Fig. 6. (Color) Maps: best configuration for LMP emplacements for outlet soil loss (Point 1); boxplots: sediment trapping coefficient for outlet for $\mathbf{r}$ varying from 0.3 to 0.7

Table 2. Sobol Sensitivity Indices

\begin{tabular}{|c|c|c|c|c|c|c|c|c|c|}
\hline \multirow{2}{*}{$\begin{array}{l}\text { Parameter } \rightarrow \\
\text { Points }\end{array}$} & \multirow[b]{2}{*}{ First $ð \mathrm{~S}_{\mathrm{i}} \mathrm{P}$} & \multicolumn{2}{|l|}{$r$} & \multicolumn{3}{|c|}{$\mathrm{p}$} & \multicolumn{3}{|c|}{ bw } \\
\hline & & Total $\partial \mathrm{S}_{\mathrm{T}} \mathrm{P}$ & $\mathrm{S}_{\mathrm{T}}-\mathrm{S}_{\mathrm{i}}$ & First $\partial \mathrm{S}_{\mathrm{i}} \mathrm{p}$ & Total $\partial \mathrm{S}_{\mathrm{T}} \mathrm{P}$ & $\mathrm{S}_{\mathrm{T}}-\mathrm{S}_{\mathrm{i}}$ & First $\partial \mathrm{S}_{\mathrm{i}} \mathrm{P}$ & Total $\partial S_{\mathrm{T}} \mathrm{P}$ & $\mathrm{S}_{\mathrm{T}}-\mathrm{S}_{\mathrm{i}}$ \\
\hline 1 & 0.9172 & 0.9926 & 0.0754 & 0.0088 & 0.0846 & 0.0758 & 0.0038 & 0.0716 & 0.0678 \\
\hline 2 & 0.5716 & 0.9987 & 0.4271 & 0 & 0.4217 & 0.4271 & 0.0141 & 0.4085 & 0.3944 \\
\hline 3 & 0.6181 & 0.9236 & 0.3055 & 0.0778 & 0.3733 & 0.2955 & 0.0094 & 0.3166 & 0.3072 \\
\hline Mean & 0.7023 & 0.9716 & 0.2693 & 0.0271 & 0.2932 & 0.2661 & 0.0091 & 0.2656 & 0.2565 \\
\hline
\end{tabular}

Thus, the interaction among these parameters has the same order of magnitude at Points 2 and 3. Table 2 indicates that $70 \%$ of the simulated soil loss is explained by $\mathbf{r}$ when taking the average of all measurement points.

\section{Conclusion}

The present numerical analysis provides a framework for studying the influence of the density and upslope-downslope locations of LMPs on soil loss response. Using Sobol methods to calculate sensitivity indices, our procedure provides information regarding the individual or combined sensitivities of the tested parameters. In the present case study, soil losses predicted by MHYDAS-Erosion are more sensitive to the overall density of LMPs (r) than to their upstream-downstream gradient ( $\mathrm{p}$ and bw). The hierarchy of parameter sensitivities arises from the first-order Sobol indices, which show that $70 \%$ of the simulated soil loss is explained by $\mathbf{r}$ when taking the average of all measurement points.
The model response of normalized soil loss also showed that the upstream-downstream gradient (p) was not the key sensitivity parameter but could significantly affect MHYDAS-Erosion output via interactions. Different values of normalized soil losses are possible for given values of $r$, according to variations in the $p$ values. This point confirms that the efficiency of LMPs is linked to their location within the catchment.

Therefore, the layout of the LMP emplacement must be properly addressed. An appropriate recommendation regarding where the LMPs should be applied is crucial for the sediment trapping efficiency. This conclusion also has strong implications for the economic aspect of LMP application because the associated cost of LMPs is strictly linked to their density within a catchment area. When the density increases, the production cost may increase as well through both productive surface losses and implantation costs. For example, reducing the sediment exportation for the Roujan catchment by $60 \%$ can be achieved with an LMP density grater than 0.4. This will drastically reduce the costs associated with LMP implantation and productive area losses. 
The numerical experiment analysis confirms the influence of LMP spatial configuration on soil-loss ratios at various spatial scales. MHYDAS-Erosion can thus be used as a toolbox to optimize the locations of LMPs in agricultural catchments.

\section{Acknowledgments}

This work was made possible by the financial support of the National Research Agency (ANR-VMC 2006) through Research Project MESOEROS21. The first author is grateful for the support of the National Council for Technological and Scientific Development (CNPQ-Brazil).

\section{References}

Boardman, J. (2006). "Soil erosion science: Reflections on the limitations of current approaches." CATENA, 68(2-3), 73-86.

Cammeraat, L. H., and Imeson, A. C. (1999). "The evolution and significance of soil-vegetation patterns following land abandonment and fire in Spain." CATENA, 37(1-2), 107-127.

Cerdan, O., Le Bissonnais, Y., Couturier, A., and Saby, N. (2002). "Modelling interrill erosion in small cultivated catchments." Hydrol. Processes, 16(16), 3215-3226.

Cheviron, B., et al. (2011). "Comparative sensitivity analysis of four distributed erosion models." Water Resour. Res., 47(1), W01510.

Cheviron, B., Gumiere, S. J., Le Bissonnais, Y., Raclot, D., and Moussa, R. (2010). "Sensitivity analysis of distributed erosion modelsFramework." Water Resour. Res., 46(8), W08508.

Colin, F., Moussa, R., and Louchart, X. (2012). "Impact of the spatial arrangement of land management practices on surface runoff for smal catchments." Hydrol. Processes, 26(2), 255-271.

Courant, R., Friedrichs, K., and Lewy, H. (1928). "Uber die partiellen Differenzengleichungen der mathematischen Physik." Math. Ann., 100(1), 32-74.

Deletic, A. (2001). "Modelling of water and sediment transport over grassed areas." J. Hydrol., 248(1-4), 168-182.

Deletic, A. (2005). "Sediment transport in urban runoff over grassed areas." J. Hydrol., 301(1-4), 108-122.

Deletic, A., and Fletcher, T. D. (2006). "Performance of grass filters used for stormwater treatment-A field and modelling study." J. Hydrol., 317(3-4), 261-275.

Doherty, J. (2004). "PEST: Model-independent parameter estimation." User manual, 5th Ed., Watermark Numerical Computing, Brisbane, Australia.

Fitzjohn, C., Ternan, J. L., and Williams, A. G. (1998). "Soil moisture variability in a semi-arid gully catchment: Implications for runoff and erosion control." CATENA, 32(1), 55-70.

Frey, H. C., and Patil, S. R. (2002). "Identification and review of sensitivity analysis methods." Risk Anal., 22(3), 553-578.

Fryirs, K. A., Brierley, G. J., Preston, N. J., and Kasai, M. (2007). "Buffers, barriers and blankets: The (dis)connectivity of catchment-scale sediment cascades." CATENA, 70(1), 49-67.

Gumiere, S. J., et al. (2011a). "MHYDAS-Erosion: A distributed singlestorm water erosion model for agricultural catchments." Hydrol. Process, 25(11), 1717-1728.

Gumiere, S. J., Le Bissonnais, Y., and Raclot, D. (2009). "Soil resistance to interrill erosion: Model parameterization and sensitivity." CATENA, 77(3), 274-284.

Gumiere, S. J., Le Bissonnais, Y., Raclot, D., and Cheviron, B. (2011b). "Vegetated filter effects on sedimentological connectivity of agricultural catchments in erosion modelling: A review." Earth Surf. Process. Landforms, 36(1), 3-19.

Hall, J. W., Tarantola, S., Bates, P. D., and Horritt, M. S. (2005). "Distributed sensitivity analysis of flood inundation model calibration." J. Hydraul. Eng., 10.1061/(ASCE)0733-9429(2005)131:2(117), 117-126.

Helton, J. C. (1993). "Uncertainty and sensitivity analysis techniques for use in performance assessment for radioactive waste disposal.” Reliab. Eng. Syst. Saf., 42(2-3), 327-367.
Iooss, B., Ribatet, M., and Marrel, A. (2009). "Global sensitivity analysis of stochastic computer models with joint metamodels." 〈http://hal .archives-ouvertes.fr/hal-00232805/en〉 (Jan. 13, 2009).

Lagacherie, P., Rabotin, M., Colin, F., Moussa, R., and Voltz, M. (2010). "Geo-MHYDAS: A landscape discretization tool for distributed hydrological modeling of cultivated areas." Comput. Geosci., 36(8), 1021-1032.

Lecomte, V. (1999). "Transfers of pesticides by the run-off and erosion from plot to catchment. Spatial modeling." Ph.D. thesis, ENGREF et INRA-Orléans.

Lee, P., Smyth, C., and Boutin, S. (2004). "Quantitative review of riparian buffer width guidelines from Canada and the United States." J. Environ. Manage., 70(2), 165-180.

Lilburne, L., and Tarantola, S. (2009). "Sensitivity analysis of spatial models.” Int. J. Geog. Inf. Sci., 23(2), 151-168.

Marrel, A., Iooss, B., Da Veiga, S., and Ribatet, M. (2010). "Global sensitivity analysis of stochastic computer models with joint metamodels." 〈http://hal.archives-ouvertes.fr/hal-00525489/fr/〉 (May 22, 2012).

Marrel, A., Iooss, B., Van Dorpe, F., and Volkova, E. (2008). "An efficient methodology for modeling complex computer codes with Gaussian processes." Comput. Stat. Data Anal., 52(10), 4731-4744.

Morel-Seytoux, H. J. (1978). "Derivation of equations for variable rainfall infiltration." Water Resour. Res., 14(4), 561-568.

Moussa, R. (1996). "Analytical Hayami solution for the diffusive wave flood routing problem with lateral inflow." Hydrol. Processes, 10(9), $1209-1227$.

Moussa, R., and Bocquillon, C. (1996). "Algorithms for solving the diffusive wave flood routing equation." Hydrol. Processes, 10(1), 105-123.

Moussa, R., Voltz, M., and Andrieux, P. (2002). "Effects of the spatial organization of agricultural management on the hydrological behaviour of a farmed catchment during flood events." Hydrol. Processes, 16(2), 393-412.

Observatoire Méditerranéen de l'Environnement Rural et de l'Eau (OMERE). (2009). "OMERE: Long-term hydro-meteorological observatory." 〈http://www.umr-lisah.fr/omere〉 (Dec. 9, 2009).

R Development Core Team. (2010). R: A language and environment for statistical computing, R Foundation for Statistical Computing, Vienna, Austria.

Saltelli, A. (2002). "Making best use of model evaluations to compute sensitivity indices." Comput. Phys. Commun., 145(2), 280-297.

Saltelli, A., et al. (2008). Global sensitivity analysis: The primer, Wiley, Chichester, U.K.

Saltelli, A., Annoni, P., Azzini, I., Campolongo, F., Ratto, M., and Tarantola, S. (2010). "Variance based sensitivity analysis of model output. Design and estimator for the total sensitivity index." Comput. Phys. Commun., 181(2), 259-270.

Saltelli, A., Chan, K., and Scott, E. M. E. (2000). Sensitivity analysis, Wiley, London.

Saltelli, A., Tarantola, S., Campolongo, F., and Ratto, M. (2004). Sensitivity analysis in practice. A guide to assessing scientific models, Wiley, London.

Saltelli, A., Tarantola, S., and Chan, K. P. S. (1999). "A quantitative model independent method for global sensitivity analysis of model output." Technometrics, 41(1), 39-56.

Sobol, I. M. (1993). "Sensitivity estimates for nonlinear mathematical models." Math. Model. Comput. Exp., 1, 407-417.

Spear, R., Grieb, T. M., and Shang, N. (1994). "Parameter uncertainty and interaction in complex environmental models." Water Resour. Res., 30(11), 3159-3169.

Van Nieuwenhuyse, B. H. J., Antoine, M., Wyseure, G., and Govers, G. (2011). "Pattern-process relationships in surface hydrology: Hydrological connectivity expressed in landscape metrics." Hydrol. Processes, 25(24), 3760-3773.

Wuertz, D., et al. (2010). "fOptions: Basics of option valuation." 〈http:// cran.r-project.org/package $=$ fOptions $\rangle$ (Jun. 24, 2013).

Young, P. C. (1978). Modeling, identification and control in environmental systems, G. C. Vansteenkiste, ed., North Holland, Amsterdam, Netherlands, $103-135$. 